\title{
A Qualitative Study of Attitudes Toward Error in Patients Facing Brain Tumour Surgery
}

\author{
Mark Bernstein, Dawn Potvin, Douglas K. Martin
}

\begin{abstract}
Background: Medical error is an extremely important component of patient safety and requires intense study. The present investigation undertook to examine patients' perceptions and attitudes regarding medical error. Methods. Qualitative case study methodology was used. We conducted 30 face-to-face interviews with patients within one week of undergoing a neurosurgical operation for a brain tumour. Interviews were audiotaped and transcribed and the data subjected to thematic analysis. Results: Three overarching themes emerged from the data: 1) trust in the patient's surgeon was of paramount importance; 2) patients'views toward medical error varied between fear and vulnerability to no concern; and 3) discussion of error was felt to be beneficial as it could help the medical profession decrease future errors and could help dispel the patient's fear and anxiety about the upcoming surgery. Conclusions: Patients'trust in their physician/surgeon is of paramount importance in allaying their fears about the possible occurrence and impact of medical error during their treatment. The level of concern about error varies among patients, but most felt that discussion of error was a good thing.
\end{abstract}

RÉSUMÉ: Une étude qualitative des attitudes face à l'erreurmédicale chez les patients qui doivent subirune chirurgie pour tumeur cérébrale. Introduction: L'erreur médicale est un élément extrêmement important de la sécurité du patient et mérite une étude attentive. Ce travail examine les perceptions et les attitudes des patients concernant l'erreur médicale. Méthodes: Il s'agit d'une étude qualitative de cas. Nous avons effectué des entrevues face-à-face avec des patients dans la semaine précédant une intervention neurochirurgicale pour une tumeur cérébrale. Les entrevues ont été enregistrées sur bande audio puis transcrites et les données ont ensuite été soumises à une analyse thématique. Résultats: Trois thèmes principaux ressortent de ces données: 1) la confiance envers le neurochirurgien était d'une extrême importance; 2) le point de vue des patients sur l'erreur médicale était très varié, allant de la crainte et de la vulnérabilité à l'absence de préoccupation; et 3) la discussion sur l'erreur était perçue comme étant bénéfique parce qu'elle pouvait aider la profession médicale à diminuer les erreurs à l'avenir et dissiper la crainte et l'anxiété des patients concernant leur chirurgie imminente. Conclusions: La confiance des patients envers leur médecin/chirurgien est extrêmement importante pour apaiser leurs craintes d'une erreur médicale et de ses répercussions pendant leur traitement. Le niveau de préoccupation à ce sujet varie parmi les patients, mais la plupart des participants considéraient que la discussion était souhaitable.

Can. J. Neurol. Sci. 2004; 31: 208-212

Reporting of adverse events (ie. complications) is essential for all health care providers and particularly for surgeons, whose patients' complications can produce dramatic and catastrophic consequences. ${ }^{1}$ Furthermore, it is a moral obligation for health care professionals to attempt to develop strategies for minimising the occurrence of medical errors which might contribute to adverse events.

Medical error has been studied ${ }^{2-9}$ and retrospective chart reviews have reported that error is common and results in significant morbidity and mortality for hospitalized patients. Some novel prospective research is also ongoing. ${ }^{10}$ When error is discussed openly amongst medical colleagues, resident trainees, nurses, other members of the health care team, and patients, it helps produce a culture less dominated by fear and recrimination and more conducive to learning from our errors

From the Division of Neurosurgery, Toronto Western Hospital, University Health Network (MB, DP), Department of Health Policy, Management and Evaluation (DKM), and Joint Center for Bioethics (MB, DKM), University of Toronto, Toronto, ON Canada.

Received June 25, 2003. Acceptedinfinalform September 11, 2003. Reprint requests to: Mark Bernstein, Department of Surgery, University of Toronto, Division of Neurosurgery, Toronto Western Hospital, 399 Bathurst Street, 4W451, Toronto, Ontario M5T2S8 Canada 
and developing systems to decrease their occurrence and/or their producing harm to patients. Open discussion of such errors might even be expected to lead to lowering of the rate of errors.

Public survey of stakeholders involved in difficult medical decisions or clinical studies have appeared in the literature, ${ }^{11-15}$ and the proper design of questionnaires to perform such studies has been described. ${ }^{16,17}$ Such surveys can shed light on numerous aspects of the patients' experience, including their expectations about treatment outcomes. ${ }^{12,15}$ Alternate views suggest that such surveys have little place in deciding what is morally right or wrong. ${ }^{18}$

However, there are few reports on patients'attitudes towards error, ${ }^{9,19}$ and these have not involved patients facing a major intervention such as brain surgery. We felt that interviewing real patients undergoing major surgery would yield different and more relevant results than interviewing nonpatients or healthy volunteers. The purpose of the present study was to attempt to determine what patients' views are toward the existence of medical error and how it might affect them.

\section{Methods}

\section{Design}

This study involved qualitative interviews with patients preparing for brain tumour surgery.

\section{Setting/participants}

Participants were patients preparing for surgery for a brain tumour in the practice of one neurosurgeon (MB). Brain tumour patients only were selected to provide at least one degree of homogeneity among the study subjects and logistically because these patients constitute the majority of cases in the neurosurgeon's (MB) practice. After informed consent for surgery was obtained, patients were asked to participate in the study. Exclusion criteria included: 1) patients scheduled for surgery other than brain tumour surgery; 2) those who did not speak English well; 3) those who were of diminished capacity and/or dysphasic from the tumour; and 4) those who were felt not to be psychologically able to participate. The latter assessment was based on a subjective decision by the neurosurgeon and was felt important in order to spare particularly "fragile" patients undue psychological harm.

\section{Sample size}

Thirty interviews were sought. This number was selected because similar qualitative studies on sensitive issues have used comparable numbers of patients ${ }^{20,21}$ and it was felt that "saturation" would obtain before this number was reached. Saturation is an expression qualitative researchers use to describe the situation when no new concepts arise during analysis of successive interviews. ${ }^{22}$

\section{Data collection}

An open-ended face-to-face interview about patients' attitudes toward medical error was conducted on each patient less than one week prior to the scheduled surgery. It was felt that less bias would be introduced in pre-operative as opposed to postoperative interviews. The important issue of attitudes toward disclosure of error ${ }^{9,19,23}$ was not addressed. The interviews were based on a guide, but themes were explored as they arose (see the Figure for Interview Guide). All interviews were audiotaped and transcribed. Demographic data including age, sex, occupation, marital status, education, type of surgery, and diagnosis were also collected.

\section{Data analysis}

Data analysis consisted of a modified thematic analysis organized into two phases: open and axial coding. ${ }^{24}$ In open coding, data were read and fractured by identifying chunks of data that relate to one idea. In axial coding, similar ideas were organized into overarching themes.

The interpretive validity of the findings were addressed in three ways: ${ }^{25}$ 1) two researchers participated in the development of the coding framework; 2) all research activities were rigorously documented to permit critical appraisal of the methods $;{ }^{26}$ and 3) a draft report was distributed to a subset of the study participants and comments were invited as a "member

This interview is about your attitudes towards medical error. What we mean by error is anything that doesn't go perfectly during your surgery or in your hospital care. This could mean small things like contamination of an instrument requiring it to be sterilized before the surgeons go on. It could mean a piece of equipment breaking down and the surgeons having to wait for a new one. It could mean accidentally cutting the covering of your brain when the surgeons are turning the bone flap if its very stuck to your bone. It could mean forgetting to reorder a drug you had been on before the surgery. In the worst instance it means something like operating on the wrong side of your head. Minor errors are common while major ones are uncommon. Most complications, like a weak leg after surgery, are not caused by an error but are due to the reaction of the brain from all the manipulation the surgeon needs to do to remove your tumor. This is what we mean by error.

1. Do you have any questions about that?

2. Have you ever thought about error? Tell me about that.

3. How do you feel about the possibility of an error happening during your surgery?

Tell me more.

4. How does talking about all of this make you feel? Tell me more.

5. Would you have preferred not having had this conversation at all prior to your surgery?

Tell me more.

6. Do you have anything you would like to add?

Figure: Interview guide 
check". The participants verified the accuracy of the report and the reasonableness of the findings.

\section{Research ethics}

All data were kept confidential. Audiotapes and transcriptions were rendered anonymous, and kept in secure storage. Participation was entirely voluntary with no coercion, and informed consent was obtained. The study protocol was approved by the Research Ethics Board of the University Health Network.

\section{RESULTS}

\section{Patient information}

Thirty patients were interviewed during a five-month working period (ie. seven total months during which the surgeon was away for two months) ending November 2002. During this time period, a total of 52 brain tumour operations were performed; thus $30 / 52$ or $57 \%$ of patients requiring brain tumour surgery were eligible for the study. No patient who was asked $(0 \%)$ declined to participate in the study. One patient who agreed to participate had to drop out of the study as she was emotionally unable to complete the interview. All but three interviews were conducted by a nurse practitioner who does not work directly with the neurosurgeon (DP). Demographic data for the 30 patients who completed the interview are shown in the Table.

\section{Thematic analysis}

In the overwhelming majority of the 30 interviews, positive feelings on the part of the patient were brought out in the interview, as opposed to negative or anxiety-rich sentiments. The narrative remarks describing these positive feelings could be reduced to the emergence of three overarching themes. These themes are described and illustrated by verbatim quotes from patient interviews.

\section{Trust}

The most predominant and repeating theme that emerged is trust. Patients' trust in the surgeon and health care system appears to give them the strength to go forward with a difficult decision, generally without much self-doubt or second-guessing.

"You can be very confident in your surgeon and there still can be an error. It just makes you feel comfortable going through the process if you have confidence in the doctor."

This trust appears to be based on patients' belief in the surgeon's experience and competence. This perception develops from a number of sources including word of mouth recommendations from other patients and other physicians (eg. the referring physician), the profile of the surgeon from media sources and/or the Internet, and one-on-one discussions with the surgeon. These patients described the characteristics that generated feelings of trust, which include: knowledge, skill, competence, and experience; directness, openness, or "straightness"; willingness to answer questions; honesty; conscientiousness; and self-confidence. Ability for the surgeon to give clear and simple explanations while remaining personable, and a "welcoming" friendly, humane nature were also highly valued.

"He's very upfront, he deals with me directly, he answers my questions... I had a friend who had a brain tumour and he was
Table: Demographic data on 30 patients interviewed

\begin{tabular}{ll}
\hline Age (years) & $\begin{array}{l}\text { Range 18-83 } \\
\text { Mean 45 } \\
\text { Median 55 }\end{array}$ \\
Sex & $\begin{array}{l}\text { Female 16 } \\
\text { Male 14 }\end{array}$ \\
Marital status & Married 21 \\
& $\begin{array}{l}\text { Single 7 } \\
\text { Widowed 2 }\end{array}$ \\
& Post-secondary school 14 \\
Education & Secondary school 10 \\
& Public school 6 \\
& Craniotomy 23 \\
Surgery & Stereotactic biopsy 7 \\
& Malignant tumour 25 \\
Pathology & Benign tumour 5
\end{tabular}

her surgeon ... she spoke very highly of him. I know of him in the field, I know his name, I know his reputation. I met him and I like him."

\section{Feelings about error vary}

The second theme is that patients' feelings about error vary. Some patients are concerned about error and feel vulnerable and scared, but they overcome their concern by trusting their surgeon.

"And a slip of the scalpel ... you think about these things, but I ... have confidence in him and I'll just have to be, you know, I will just assume everything will go right."

Some are more preoccupied with the disease itself than with the specter of error.

"From my readings, I think that the disease is worse than the risk of error. I have trust and faith in the surgeon and his staff."

Other patients are simply not concerned about error because it is just in their nature not to worry and/or they feel they cannot control the situation.

"I don't worry about it. I don't worry about things that I can't control."

\section{Discussion is good}

The third theme is that patients feel that discussing error is a good thing. Discussing error openly might help to prevent future errors, for themselves or for other patients and also helps to dispel anxiety and relieve stress.

"Knowledge to me, at least, does not increase anxiety. If anything, it dispels it."

It also demonstrates to some patients that if the health care team is concerned enough to ask these questions, it must reflect positively on them.

"I think it's a good thing to talk about ... I like to know that 
you are this concerned about errors occurring. So, if anything, it helps my confidence."

\section{Discussion}

In this study we examined patients' attitudes towards error. There have been very few studies assessing patients'perceptions about error and they address primarily what patients wish to know about disclosure of error. ${ }^{9,19}$ Witman et $\mathrm{al}^{9}$ surveyed 149 patients randomly selected from an academic general medicine outpatient clinic to assess what patients would want to know about errors. They found that essentially all patients desired some knowledge about even minor errors. Desire for referral to another surgeon ranged from $14 \%$ following a minor mistake to $65 \%$ following a major error. Patients were more likely to consider litigation if not informed of the error.

The current study is unique in that we described patients' views toward medical error. It was innovative in that: 1) we used qualitative in-depth open-ended interviews as opposed to questionnaires; 2) our participants were real patients who were within one week of undergoing a major surgical intervention for a life-threatening condition with significant possibility for morbidity, as opposed to a minor intervention or no intervention; and 3) the focus was on the patient's attitudes and perceptions of their level of concern about error, not how and what they wish to be informed of if error occurred.

Our main finding was that, when asked about medical error, these patients talked about trust. Trust is an important component of most social interactions, particularly when there is a perceived asymmetry of power, as there is in the relationship between patient and physician. Trust in the doctor-patient relationship ${ }^{27}$ has been extensively explored and has been examined in a variety of disparate contexts and settings such as breast cancer screening, ${ }^{28}$ unmet expectations of care, ${ }^{29}$ the emotional content of the nurse-patient relationship, ${ }^{30}$ the relationship of unrelieved pain to trust levels, ${ }^{31}$ how to quantify trust, ${ }^{32}$ and theoretical modeling of trust, ${ }^{33}$ to cite a few. The whole concept of trust has also been examined by sociological theorists. For example, Simmel's model has been interpreted as being composed of three elements: 1) expectation, or the state reached at the end of the trust process; 2) interpretation, or the idea that humans' experience gives rise to the basis for trust; and 3) suspension, which is the bracketing of the unknowable which enables the mental leap of trust from interpretation to expectation. ${ }^{34}$

We asked patients about their feelings toward medical error but, by and large, they chose voluntarily to talk about trust. In their view trust is an important mitigator of their level of concern about medical error befalling them during major brain surgery. Similarly, McKneally and Martin $^{20}$ interviewed patients following recovery from esophagectomy for cancer and found that trust in the surgeon was the overwhelmingly powerful motivator for patients' acceptance of major surgery and in particular for providing informed consent. In our study, trust was an even more powerful concept because the interviews were conducted prior to life-threatening surgery as opposed to after recovery, and the patients did not know what their outcome would be.

McKneally and Martin appropriately admonish that such trust must not replace ethical and legal requirements of the consent process. Similarly, based on our findings, we must not allow our patients'profound trust in their care givers to subvert the ethical and legal requirement to disclose information that they would reasonably wish to know about their disease, the risks of surgery and/or other treatment, and about the possibility of error and the necessity to disclose errors if they occur.

These findings are not generalizable to other brain surgery patients, or any other patients. However, this was an exploratory study of a topic that, to our knowledge, has not been studied previously. Moreover, the goal of qualitative studies like this one is to describe the views of the study participants, not to generalize.

Patients in this study were selected from the practice of a neurosurgeon with a special interest in brain tumours. Because of the relatively urgent nature of brain tumour surgery, the time gap between the initial consultation, consent for surgery and the study interview was short (usually less than a week) and it is possible that richer interviews would have been obtained if patients had had more time to think about the issue of error. Similarly, perhaps the shock of learning the patient required brain tumour surgery impacted negatively on their clarity of thinking and/or they were preoccupied with issues other than participating in a research study. There is no standard validated interview guide for this type of study and it is possible that the best questions were not asked and/or themes were not developed adequately.

Trust in one's surgeon was extremely important to these patients' views toward medical error. While human beings' fundamental strength and courage must be acknowledged as the single most important factor which empowers patients to make tough medical decisions, arguably the most important external factor in the evolution of the patient-doctor relationship which allows patients to go forward with invasive interventions with major potential negative consequences is trust in their physician and/or the system.

This information reminds us that our patients place profound trust in us. It also shows us that patients feel that discussing error is good and this fact may help empower clinicians to talk more openly about error with our patients. These observations could alter how clinicians think about patients' views about error and remind us that it may be safer than we think to talk about it with them. This could help remove some fear and anxiety for both our patients and clinicians.

\section{REFERENCES}

1. Cabantog A, Bernstein M. Complications of first craniotomy for intra-axial brain tumor. Can J Neurol Sci 1994; 21:213-218.

2. de Laval MR, Carthey J, Wright DJ, et al. Human factors and cardiac surgery: a multicenter study. J Thor Cardiovasc Surg 2000; 119:661-672.

3. Etchells E, Bernstein M. Improving patient safety: just do it. Healthcare Papers 2001; 2:59-65.

4. Gawande AA, Thomas EJ, Zinner MJ, Brennan TA. The incidence and nature of surgical adverse events in Colorado and Utah in 1992. Surgery 1999; 126:66-75.

5. Hobgood C, Peck CR, Gilbert B, Chappell K, Zou B. Medical errors - what and when: what do patients want to know? Acad Emerg Med 2002; 9:1156-1161.

6. Latham SR. System and responsibility: three readings of the IOM report on medical error. Am J Law \& Med 2001; 27:163-179.

7. Leape LL, Brennan TA, Laird N, et al. The nature of adverse events 
in hospitalized patients. Results of the Harvard Medical Practice Study II. N Engl J Med 1991; 324:377-384.

8. Vincent C, Neale G, Woloshynowych M. Adverse events in British hospitals: preliminary retrospective record review. $\mathrm{Br}$ Med J 2001; 322:517-519.

9. Witman AB, Park DM, Hardin SB. How do patients want physicians to handle mistakes? A survey of internal medicine patients in an academic setting. Arch Intern Med 1996; 156:2565-2569.

10. Bernstein M, Massicotte E: Prospective error recording in surgery: a feasibility study in 500 neurosurgical cases. Evidence-Based Surgery 2003; 1:57-62.

11. Fung D, Cohen M. What do patients value most in their anesthesia care? Can J Anesth 2001; 48:12-19.

12. Holzner B, Kemmler G, Kopp M, et al. Preoperative expectations and postoperative quality of life in liver transplant survivors. Arch Phys Med Rehabil 2001; 82:73-79.

13. Jacobson JA, Kasworm EM, Battin MP, et al. Decedents' reported preferences for physician-assisted death: a survey of informants listed on death certificates in Utah. J Clin Ethics 1995; 6:184-192.

14. Singer PA, Martin DK, Kelner M. Quality end-of-life care. Patients' perspectives. JAMA1999; 281:163-168.

15. Wilson SJ, Saling MM, Kincade P, Bladin PF. Patient expectations of temporal lobe surgery. Epilepsia 1998; 39:167-174.

16. Babbie ER. Survey Research Methods. Wadsworth, Inc., 1990:118-139.

17. Britten N. Qualitative interviews in medical research. Br Med J 1995; 311:251-255.

18. Pellegrino ED. The limitation of empirical research in ethics. J Clin Ethics 1995; 6:161-162.

19. Gallagher TH, Waterman AD, Ebers AG, Fraser VJ, Levinson W. Patients' and physicians' attitudes regarding the disclosure of medical errors. JAMA2003; 289:1001-1007.

20. McKneally MF, Martin DK. An entrustment model of consent for surgical treatment of life-threatening illness: perspective of patients requiring esophagectomy. J Thorac Cardiovasc Surg 2000; 120:264-269.

21. Scott G, Whyler N, Grant G. A study of family carers of people with a life-threatening illness 1 : the carers'needs analysis. Int $\mathbf{J}$ Palliat Nurs 2001; 7:290-291.
22. Strauss A, Corbin J. Basics of Qualitative Research: Grounded Theory Procedures and Techniques. Beverly Hills: Sage Publications Inc; 1990: 188.

23. Bernstein M, Hebert PC, Etchells E. Patient safety in neurosurgery: detection of errors, prevention of errors, and disclosure of errors. Neurosurgery Quarterly 2003; 13:125-137.

24. Strauss A, Corbin J. Basics of Qualitative Research: Techniques and Procedures of Developing Grounded Theory. Thousand Oaks, CA: Sage Publications Inc., 1998: 55-242.

25. Altheide DL, Johnson JM. Criteria for assessing interpretive validity in qualitative research. In: Denzin NK, Lincoln YS, eds. Handbook of Qualitative Research. Thousand Oaks, Sage Publications Inc, 1994: 485-499.

26. Mays N, Pope C. Rigour and qualitative research. Br Med J 1995; 311:109-112.

27. Chin JJ. Doctor-patient relationship: a covenant of trust. Singapore Med J 2001; 42:579-581.

28. Helmes AW, Bowen DJ, Bengel J. Patient preferences of decisionmaking in the context of genetic testing for breast cancer risk. Genet Med 2002; 4:150-157.

29. Bell RA, Kravitz RL, Thom D, Krupat E, Azari R. Unmet expectations for care and the patient-physician relationship. J Gen Intern Med 2002; 17:817-824.

30. de Raeve L. The modification of emotional responses: a problem for trust in the nurse-patient relationship. Nurs Ethics 2002; 9:465471.

31. Peter E, Watt-Watson J. Unrelieved pain: an ethical and epistemological analysis of distrust in patients. Can J Nurs Res 2002; 34:65-80.

32. Hall MA, Zheng B, Dugan E, et al. Measuring patients'trust in their primary care providers. Med Care Res Rev 2002; 59:293, 318.

33. Anheier $\mathrm{H}$, Kendall J. Interpersonal trust and voluntary associations: examining three approaches. Br J Sociol 2002; 53:343-362.

34. Mollering G. The nature of trust: from Georg Simmel to a theory of expectation, interpretation, and suspension. Sociology 2001; $35: 403-420$ 